\title{
Comparison of Axillary Digital and Infrared Forehead Thermometer
}

\author{
Srinidhi, $\mathrm{M}^{1}$, Ranganath K. $\mathrm{R}^{2 *}$, Roshni Jennifer ${ }^{3}$
}

\author{
${ }^{1}$ Post graduate (M.D Pediatrics), Department of Pediatrics, Dr. B. R Ambedkar Medical College, No 19, Venkateshpuram, \\ Kadugondanahalli, Bengaluru, Karnataka 560045, India \\ ${ }^{2}$ Associate Professor, Department of Pediatrics, Dr. B. R Ambedkar Medical College, No 19, Venkateshpuram, Kadugondanahalli, \\ Bengaluru, Karnataka 560045, India \\ ${ }^{3}$ M.D Pediatrics, Department of Pediatrics, Dr. B. R Ambedkar Medical College, No 19, Venkateshpuram, Kadugondanahalli, \\ Bengaluru, Karnataka 560045, India
}

DOI: $10.36347 /$ sjams.2022.v10i01.013

| Received: 11.12.2021 | Accepted: 13.01.2022 | Published: 19.01.2022

*Corresponding author: Ranganath K. R

Associate Professor, Department of Pediatrics, Dr. B. R Ambedkar Medical College, No 19, Venkateshpuram, Kadugondanahalli, Bengaluru, Karnataka 560045, India

Abstract Original Research Article

Introduction: Although digital thermometers have made the temperature recording easy, quick and safe, with the risk of mercury completely excluded, there is still a risk of transmission of infection from one individual to another. Infrared thermometers offer a non-touch, rapid and convenient method of temperature recording, with virtually no risk of disease transmission. We conducted a study to assess and compare temperature recordings from an infrared forehead thermometer and axillary digital thermometer during fever, and once the fever subsides. Methods: Hundred patients attending the out-patient department of Department of Pediatrics at Dr.B.R Ambedkar medical college and hospital from September 2019 to December 2019, or those admitted in the wards with a complaint of fever were screened using two techniques - Axillary temperature recording using a digital thermometer and a forehead temperature was recorded using a non-contact infrared forehead thermometer. Patients were given antipyretics to treat the fever and temperature was again recorded once the fever subsided using the same method. Two medical personnel were trained to screen and record the respective findings from each method and they were blinded from the other outcome of other recording. Results: The mean IFR temperature measured in the febrile phase was $100.85( \pm 0.76)$, which was significantly higher than the mean AD temperature, 100.21 ( \pm 0.74). (p-value <.0001). In the afebrile phase as well, the mean IFR temperature was significantly higher than the mean AD temperature. Conclusion: IFR thermometers do provide an advantage of no-touch technique over the digital thermometer. However, as the results showed a weak correlation between IFR and axillary digital recordings, it is suggested that IFR thermometers be used for screening of children for fever as it decreases the contact and reduces the infection.

Keywords: Axillary temperature, Infrared thermometer, Digital thermometer.

Copyright $\left({ }_{0} 2022\right.$ The Author(s): This is an open-access article distributed under the terms of the Creative Commons Attribution 4.0 International License (CC BY-NC 4.0) which permits unrestricted use, distribution, and reproduction in any medium for non-commercial use provided the original author and source are credited.

\section{INTRODUCTION}

Body temperature is one of the most common and important clinical signs for fever, which occurs when hypothalamus raises the body temperature above its normal level. In a developing country like India, where many endemic disease prevail, screening for fever is of huge importance in detecting potential diseases early enough to treat them most effectively.

Body temperature is measured using a thermometer, which may function according to one of two types as used currently - digital thermometer and a non-contact infrared thermometer. Both types of thermometers differ in their technology. Digital thermometers are contact thermometers, which function by putting a voltage across its metal probe and measuring how much current flows through it. In contrast, the non-contact forehead infrared thermometry measures temperature from a distance using a sensor probe, which assesses the amount of thermal radiation (infrared) emitted from the forehead, which has rich blood flow from the temporal artery. The reliability of the temperature from a distance remains an issue since the body emits some radiations at the baseline and the surrounding substances may affect it.

Although digital thermometers have eliminated the risk of contact with mercury, there is still a risk of transmission of infection from one individual to another 
with digital thermometers. Usually they have to be placed in oral cavity or axilla for a recording of temperature. The non-contact forehead infrared thermometry on the other hand, is provides a method for safe, rapid and convenient temperature recording due to its non-touch technique and negligible risk of cross infections.

The axillary temperature recording is suggested by the "American Academy of Pediatrics and National Association of Neonatal Nurses"for measuring body temperature in pediatric patients having fever [1]. We have used axillary temperature recording in our studyfor comparison with forehead IFR. Both areas holds individual disadvantages. Axillary recordings are troublesome in children with fever since it needs cooperation from the child and a maneuver to expose the axilla [2], whereas forehead temperature is subject to fluctuation through vasoconstriction and perspiration [3].

In this pandemic of COVID-19, though infrared (IFR) thermometers have been much in use for the screening of children and adults at the entry of every building, its reliability and consistency as a body temperature measuring device in the hospitals for screening of fever needs validation [4-6].

We carried out this study to compare temperature readings from infrared forehead thermometer and axillary digital thermometer at the time of fever and to compare temperature readings from infrared forehead thermometer and axillary digital thermometer once the fever subsides.

\section{Methods}

For our study, fever was defined as an axillary temperature $\geq 99^{\circ} \mathrm{F}$ for age group between 1-2 years, and $\geq 98.6^{\circ} \mathrm{F}$ for age group between 3-10 years. Hundred patients presenting with fever to the outpatient department or admitted to the in-patient ward at the Department of Paediatrics at Dr. B.R Ambedkar Medical college and Hospital, were recruited for our study. Body temperature was measured by using two techniques - axillary temperature was taken using a digital electronic thermometer and forehead temperature was recorded using a non contact infrared forehead thermometer simultaneously. The digital thermometer was applied with the sensor in the child's armpits after activating the button power and waiting till the alarm sounded for its temperature display. An Infrared forehead thermometer was placed 1 to $3 \mathrm{~cm}$ from mid-forehead and the start button was pressed for recording. The measurement was completed in one second with a long indicator sound. Two dedicated medical personnel were trained on how to use the infrared forehead (IFR) and axillary digital (AD) thermometer. One personnel documented readings from forehead using IFR thermometer while the other medical personnel immediately documented axillary temperature using $\mathrm{AD}$ thermometer, blinded from the results of the first reading. Age, sex, the ability of the child to sit, parental declarations of fever were also recorded for each study participant.

The temperature readings at the two sites were compared.Patients were given antipyretics to treat the fever and temperature was again recorded once the fever subsided using the same method. Neonates, infants, patients unwilling to be enrolled in the study and those having perspiration during temperature measurement were excluded from our study.

The data entry, cleaning and coding was done in the Microsoft Excel and analysis was carried out using Statistical Package for Social Sciences (SPSS) software V.21.0. Categorical variables were presented as percentages while continuous parametric variables were presented as mean and standard deviation and non-parametric variables were presented as median. Comparison of readings between IFR and $\mathrm{AD}$ thermometers was done using Paired t-test. A p value of less than 0.05 was considered as statistically significant

\section{Results}

In our study, majority (39\%) of the study participants were aged between 3 to 4 years, while 35 $(35 \%)$ patients were aged between 2 to 3 years. Twenty patients were aged less than two years, while six patients were aged more than four years. Half of the study participants $(50 \%)$ were male and half $(50 \%)$ were female.

The mean IFR temperature measured in the febrile phase was 100.85 ( \pm 0.76$)$, which was significantly higher than the mean $\mathrm{AD}$ temperature, 100.21 ( \pm 0.74$)$. (p-value<.0001). In the afebrile phase as well, the mean IFR temperature was significantly higher than the mean $\mathrm{AD}$ temperature (See Table 2).

The difference between temperature measured with IFR and AD thermometers was found to be statistically significant in both febrile and afebrile phase between participants aged more than 3 years and those aged three years old or less (See Table 3). Similar observations were made for the difference between temperature measured with IFR and AD thermometers between male and female patients in both febrile and afebrile phase (See Table 4).

Bland-Altman plots were constructed for comparison of measurement of temperature in febrile and afebrile phase between infrared and digital thermometers. On Bland-Altman plot, the temperature in febrile phase measured by IFR was 0.643 units more than (overestimate) the temperature measured by DA. The limits of agreement estimated an interval of 0.0873 to 1.3733 . Additionally, the temperature in afebrile phase measured by IFR was 1.309 units more than (overestimate) that measured by DA. The limits of 
Table 1:-Distribution of age and gender.

\begin{tabular}{|l|l|}
\hline \multicolumn{2}{|l|}{ Variables } \\
\hline \multicolumn{2}{|l|}{ Age(years) } \\
\hline $1-2$ years & $20(20 \%)$ \\
\hline $2.1-3$ years & $35(35 \%)$ \\
\hline 3.1-4 years & $39(39 \%)$ \\
\hline 4.1-5years & $6(6 \%)$ \\
\hline Gender \\
\hline Males & $50(50 \%)$ \\
\hline Females & $50(50 \%)$ \\
\hline
\end{tabular}

Table 2: Comparison of temperature in febrile and afebrile between infrared and digital

\begin{tabular}{|l|l|l|l|l|l|}
\hline Device & Mean \pm SD & Range & Mean difference & t-Test score & P value \\
\hline Febrile & \multicolumn{5}{|l|}{} \\
\cline { 1 - 3 } Infra Red & $100.85 \pm 0.76$ & $99-102.4$ & 0.64 & 17.257 & $<.0001$ \\
\hline Digital & $100.21 \pm 0.74$ & $99-102$ & & & \\
\hline Afebrile \\
Infra Red & $98.62 \pm 0.53$ & $97.1-99.5$ & 1.31 & 21.417 & $<.0001$ \\
\cline { 1 - 2 } Digital & $97.31 \pm 0.73$ & $95.8-99.1$ & & & \\
\hline
\end{tabular}

Table 3: Comparison of temperature in febrile and afebrile between infrared and digital in different age group

\begin{tabular}{|c|c|c|c|c|c|c|c|}
\hline Condition & Age & Device & Mean \pm SD & Range & $\begin{array}{l}\text { Mean } \\
\text { difference }\end{array}$ & Test performed & $\begin{array}{l}\mathbf{P} \\
\text { value }\end{array}$ \\
\hline \multirow[t]{4}{*}{ Febrile } & \multirow{2}{*}{$\begin{array}{l}<=3 \\
\text { years }(n=55)\end{array}$} & Infra red & $100.92 \pm 0.73$ & $99.8-102.2$ & \multirow[t]{2}{*}{0.703} & \multirow{2}{*}{$\begin{array}{l}\text { Paired } \mathrm{t} \text { test; } \mathrm{t} \\
\text { value }=16.412\end{array}$} & \multirow[t]{2}{*}{$<.0001$} \\
\hline & & Digital & $100.21 \pm 0.73$ & 99-101.8 & & & \\
\hline & \multirow[t]{2}{*}{$>3$ years $(n=45)$} & Infra red & $100.77 \pm 0.79$ & 99-102.4 & \multirow[t]{2}{*}{0.569} & \multirow{2}{*}{$\begin{array}{l}\text { Paired } \mathrm{t} \text { test } \mathrm{t} \\
\text { value }=9.043\end{array}$} & \multirow[t]{2}{*}{$<.0001$} \\
\hline & & Digital & $100.2 \pm 0.77$ & $99-102$ & & & \\
\hline \multirow[t]{4}{*}{ Afebrile } & \multirow{2}{*}{$\begin{array}{l}=3 \\
\text { years }(n=55)\end{array}$} & Infra red & $98.58 \pm 0.57$ & $97.1-99.5$ & \multirow[t]{2}{*}{0.125} & \multirow{2}{*}{$\begin{array}{l}\text { Paired t test; } \mathrm{t} \\
\text { value }=14.684\end{array}$} & \multirow[t]{2}{*}{$<.0001$} \\
\hline & & Digital & $97.33 \pm 0.77$ & $95.8-99.1$ & & & \\
\hline & \multirow[t]{2}{*}{$>3$ years $(n=45)$} & Infra red & $98.66 \pm 0.48$ & $97.8-99.3$ & \multirow[t]{2}{*}{1.378} & \multirow{2}{*}{$\begin{array}{l}\text { Paired } \mathrm{t} \text { test; } \mathrm{t} \\
\text { value }=15.841\end{array}$} & \multirow[t]{2}{*}{$<.0001$} \\
\hline & & Digital & $97.28 \pm 0.68$ & $96.2-98.9$ & & & \\
\hline
\end{tabular}

Table 4:-Comparison of temperature in febrile and afebrile between infrared and digital in males and females

\begin{tabular}{|c|c|c|c|c|c|c|c|}
\hline Condition & Gender & Device & Mean \pm SD & Range & $\begin{array}{l}\text { Mean } \\
\text { difference }\end{array}$ & $\begin{array}{l}\text { Test } \\
\text { performed }\end{array}$ & $P$ value \\
\hline \multirow[t]{4}{*}{ Febrile } & \multirow[t]{2}{*}{$\operatorname{Female}(n=50)$} & Infra red & $100.87 \pm 0.84$ & $99-102.4$ & \multirow[t]{2}{*}{0.664} & \multirow{2}{*}{$\begin{array}{l}\text { Paired } t \text { test; } t \\
\text { value }=13.120\end{array}$} & \multirow[t]{2}{*}{$<.0001$} \\
\hline & & Digital & $100.2 \pm 0.8$ & 99-101.8 & & & \\
\hline & \multirow[t]{2}{*}{$\operatorname{Male}(n=50)$} & Infra red & $100.84 \pm 0.67$ & $99.8-102.2$ & \multirow[t]{2}{*}{0.622} & \multirow{2}{*}{$\begin{array}{l}\text { Paired t test; t } \\
\text { value }=11.298\end{array}$} & \multirow[t]{2}{*}{$<.0001$} \\
\hline & & Digital & $100.22 \pm 0.69$ & $99-102$ & & & \\
\hline \multirow[t]{4}{*}{ Afebrile } & \multirow[t]{2}{*}{$\operatorname{Female}(\mathrm{n}=50)$} & Infra red & $98.66 \pm 0.5$ & $97.8-99.5$ & \multirow[t]{2}{*}{1.34} & \multirow{2}{*}{$\begin{array}{l}\text { Paired t test; } t \\
\text { value }=16.551\end{array}$} & \multirow[t]{2}{*}{$<.0001$} \\
\hline & & Digital & $97.32 \pm 0.77$ & $95.8-99.1$ & & & \\
\hline & \multirow[t]{2}{*}{$\operatorname{Male}(\mathbf{n}=50)$} & Infra red & $98.58 \pm 0.56$ & $97.1-99.3$ & \multirow[t]{2}{*}{1.278} & \multirow{2}{*}{$\begin{array}{l}\text { Paired t test; } t \\
\text { value = } 13.862\end{array}$} & \multirow[t]{2}{*}{$<.0001$} \\
\hline & & Digital & $97.3 \pm 0.69$ & $96.2-99$ & & & \\
\hline
\end{tabular}

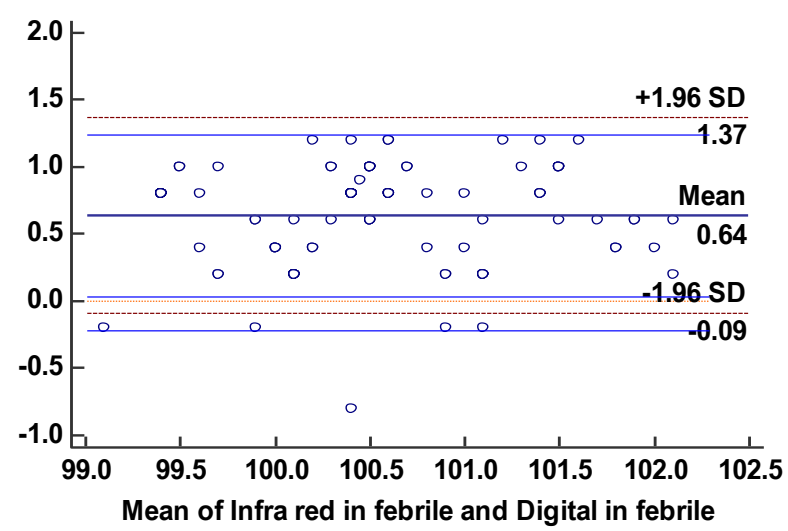

Figure 1: Bland-Altman plot for comparison of measurement of temperature in febrile between infrared and digital 


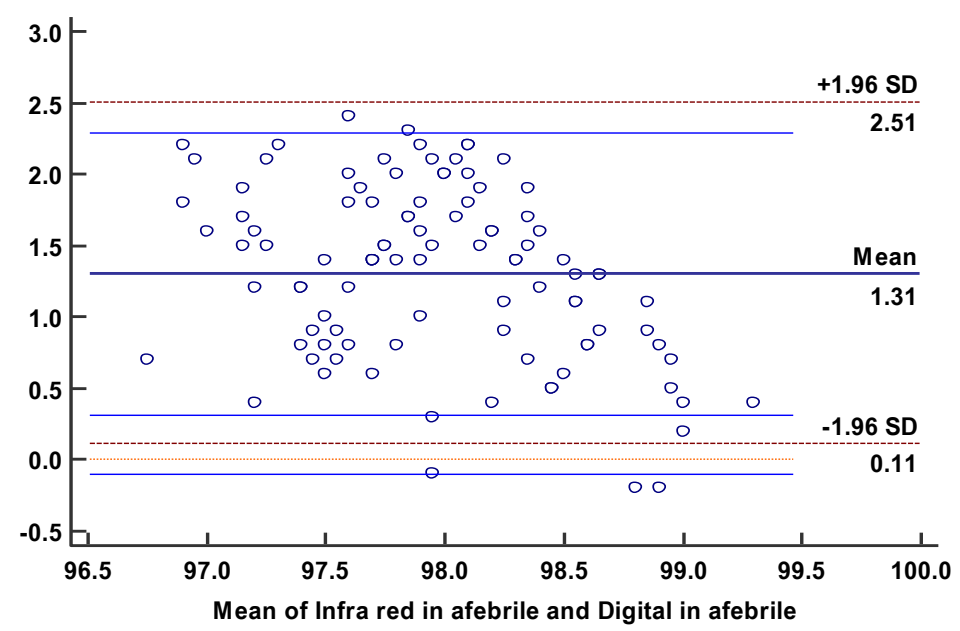

Figure 2: Blands Altman plot for comparison of measurement of temperature in afebrile between infrared and digital

\section{Discussion}

In our study, we simultaneously assessed the temperatures measured using IFR and DA. It has been observed in our study that forehead IFR thermometers recordings showed weak correlation with digital axillary measurements. Bland Altman analysis clearly showed that IFR thermometers might overestimate or underestimate the temperature by 0.643 units in febrile children and 1.309 units in afebrile children in comparison to digital thermometers.

These findings were in concordance with those reported by AtaşBerksoy E et al., [7] where the difference was by 0.55 units. Osio CE et al., [6] also reportedsimilar findings amongst 90 pediatric patients, describing a weak correlation between measurements of IFR thermometers and digital temperatures recording from tympanic, temporal artery and axillary regions. In a study by Sethi A et al., [2] the temperatures measured by digital and IFR thermometers were in poor agreement whileFranconi I et al., [8] in a recent study, also concluded that there was a statistically significant difference $\left(0.41^{\circ} \mathrm{C}\right)$ between axillary digital recordings with non-contact (infrared) forehead thermometers.

In contrast to the present study, Chiappini et $a l$., [5] showed a strong correlation $(\mathrm{r}=0.84)$ between IFR and axillary measurements. However, the authors used mercury-in-glass thermometer instead of digital thermometers. Teren et al., [9] also concluded that IFR thermometers are accurate when analysed in comparison with the gold standard rectal readings. Both studies made use of different measuring instruments.

To account for various confounding variables, the study population was statistically analysed according to age groups, gender andpresence of fever. Interestingly, IFR thermometers recordings were consistently and significantly higher than digital axillary recordings for all the subgroups. In another study by Ataş Berksoy E et al., [7], axillary digital recordings were similar to neck IFR readings irrespective of the demographic variables.

The study suffers from certain limitations. Temperature was not measured at other sites, such as the neck. Secondly, a gold standard rectal temperature recording was not assessed for comparison and further assessing diagnostic validity. Third, the reliability was recorded on the basis of a single recording rather than consecutive or multiple recordings. Lastly, IFR thermometers have an inherent limitation of being affected by the environmental conditions and in a developing country like India; the environmental conditions in the triage room cannot be completely controlled.

Overall, IFR thermometers do provide an advantage of no-touch technique over the digital thermometer. However, as the results showed a weak correlation between IFR and axillary digital recordings, it is suggested that IFR thermometers be used for screening of children for fever as it decreases the contact and reduces the infection. For more accurate recordings the findings must be reassessed with digital thermometers.

\section{CONCLUSION}

Forehead IFR temperature showed weak correlation with digital axillary recordings with a deviation of 0.643 units. Since IFR thermometers are simple, safe, and a rapid method, its routine use in the hospital settings for screening of fever is advisable in this pandemic of COVID-19. However, further studies are recommended to compare its use at other body sites and various distances from the body to have a standardized protocol of temperature recordings.

\section{REFERENCES}

1. Martin, S. A., \& Kline, A. M. (2004). Can there be a standard for temperature measurement in the 
Srinidhi, M et al; Sch J App Med Sci, Jan, 2022; 10(1): 82-86

pediatric intensive care unit?. AACN Advanced Critical Care, 15(2), 254-266.

2. Sethi, A., Patel, D., Nimbalkar, A., Phatak, A., \& Nimbalkar, S. (2013). Comparison of forehead infrared thermometry with axillary digital thermometry in neonates. Indian Pediatrics, 50(12), 1153-1154.

3. Vernon, G. (2014). Non-contact infrared thermometers. Br J Gen Pract, 64(629), 615.

4. Selent, M. U., Molinari, N. M., Baxter, A., Nguyen, A. V., Siegelson, H., Brown, C. M., ... \& Fishbein, D. B. (2013). Mass screening for fever in children: a comparison of 3 infrared thermal detection systems. Pediatric emergency care, 29(3), 305-313.

5. Chiappini, E., Sollai, S., Longhi, R., Morandini, L., Laghi, A., Osio, C. E., ... \& de Martino, M. (2011). Performance of non-contact infrared thermometer for detecting febrile children in hospital and ambulatory settings. Journal of clinical nursing, 20(9-10), 1311-1318.

6. Osio, C. E., \& Carnelli, V. (2007). Comparative study of body temperature measured with a noncontact infrared thermometer versus conventional devices. The first Italian study on 90 pediatric patients. Minerva pediatrica, 59(4), 327-336.

7. Berksoy, E. A., Băg, Ö., Yazici, S., \& Çelik, T. (2018). Use of noncontact infrared thermography to measure temperature in children in a triage room. Medicine, 97(5), e9737.

8. Franconi, I., La Cerra, C., Marucci, A. R., Petrucci, C., \& Lancia, L. (2018). Digital axillary and noncontact infrared thermometers for children. Clinical nursing research, 27(2), 180-190.

9. Teran, C. G., Torrez-Llanos, J., Teran-Miranda, T. E., Balderrama, C., Shah, N. S., \& Villarroel, P. (2012). Clinical accuracy of a non-contact infrared skin thermometer in paediatric practice. Child: care, health and development, 38(4), 471-476. 